\title{
Strategi Pemasaran dengan menggunakan Analisis SWOT Tanpa Skala Industri Pada PT X Di Jakarta
}

\author{
Arie Wicaksono \\ E-mail: arie@gmail.com \\ Program studi Manajemen Pemasaran Industri Elektronika \\ Politeknik APP Jakarta
}

\begin{abstract}
In the business competition that increasingly tight along with the development of new technology that more advanced and modern makes Companies attempted to find the quick and appropriate strategy in marketing products to fulfill industry needs. The development of industrial era that gradually grow in the various fields, especially for heavy equipment industry that need to take a strategy in order to win the competition and to obtain larger market share. This research uses quantitative descriptive research method by describing facts and explaining the situation based on facts and figures data that exist and try to analyze the truth through the data obtained. The analytical method used is SWOT Analysis of TSI (No Industry Scale) using EFAS (external factor analysis) and IFAS (internal factor analysis) analysis. The results of this study indicate that company $X$ in using the SWOT Without Industrial Scale puts the strategy of Strength $(S)>$ Opportunity (O), Strategy Opportunity $(O)>$ Weakness $(W)$, Strength Strategy $(S)>$ Threat $(T)$ and Threat Strategy> Weakness $(W)$, so that this condition that PT X is in position to utilize SO strategy which has highest score value that is $=7.6$, followed by strategy $S T=6.6, W O=6.0$ and $W T=4.8$. From these results, the strategy undertaken by company $X$ is to maintain the brand image strategy and penetrate the market to find a larger market share. Strengthening human resources (HR) needs to be done so that companies can add and train human resources, especially professional technicians.
\end{abstract}

Keywords: Strategy, SWOT Analysis, No Industry Scale 


\begin{abstract}
Abstrak
Dalam persaingan dunia bisnis yang semakin ketat serta perkembangan teknologi yang semakin canggih dan modern, membuat perusahaan berusaha mencari strategi yang cepat dan tepat dalam memasarkan produk untuk memenuhi kebutuhan industri. Perkembangan dunia industri yang terus berkembang di berbagai bidang, khususnya industri alat berat sehingga dibutuhkan suatu strategi untuk dapat memenangkan persaingan dan mendapatkan pangsa pasar yang besar. Penelitian ini menggunakan metode penelitian deskriptif kuantitatif dengan menggambarkan fakta-fakta dan menjelaskan keadaan berdasarkan fakta-fakta dan data angka yang ada dan mencoba menganalisis kebenarannya melalui data yang diperoleh. Metode analisis yang digunakan yaitu Analisis SWOT TSI (Tanpa Skala Industri) dengan menggunakan metode EFAS (analisis faktor eksternal) dan IFAS (analisis faktor internal) perusahaan. Hasil penelitian ini menunjukkan bahwa perusahaan X dalam menggunakan SWOT Tanpa Skala Indusri menempatkan strategi Strength $(S)>$ Opportunity $(O)$, Strategi Opportunity $(O)>$ Weakness $(W)$, Strategi Strength $(S)>$ Threat $(T)$ dan Strategi Threat > Weakness $(W)$, sehingga kondisi ini bahwa PT X berada pada posisi memanfaatkan strategi SO yang mempunyai nilai skor tertinggi yaitu $=7.6$, selanjutnya diikuti strategi $S T=6.6, W O=6.0$ dan $W T=4.8$. Dari hasil tersebut maka strategi yang dilakukan oleh perusahaan $X$ yaitu melakukan strategi mempertahankan citra merek dan melakukan penetrasi pasar untuk mencari pangsa pasar yang lebih besar. Penguatan sumber daya manusia (SDM) perlu dilakukan agar perusahaan dapat menambah dan melatih SDM khususnya tenaga teknisi yang professional.
\end{abstract}

Kata Kunci : Strategi, Analisis SWOT, Tanpa Skala Industri.

\section{PENDAHULUAN}

Perusahaan agar dapat bertahan dan mampu bersaing di pasar, perusahaan harus tahu bagaimana cara menyesuaikan diri dengan pasar yang terus menerus berubah. Untuk dapat mewujudkannya maka perlu diterapkan suatu strategi yang tepat dengan menggunakan analisis SWOT. Analisis SWOT merupakan alat formulasi strategi yang menganalisis dan mengidentifikasi berbagai faktor secara sistematis untuk merumuskan strategi perusahaan berdasarkan pada logika yang dapat memaksimalkan kekuatan (strengths), peluang (opportunity), namun secara bersamaan meminimalkan kelemahan (weakness) dan ancaman (threats), (Rangkuti, 2005). Semua organisasi membutuhkan pemasaran untuk mencapai tujuan dan objektifnya, jadi perusahaan memerlukan strategi yang berbeda-beda guna jangka panjang yang digunakan bagi pedoman masing-masing tingkat perusahaan. Kotler dan Armstrong (2010), strategi pemasaran merupakan logika pemasaran dan berdasarkan itu, unit bisnis diharapkan untuk mencapai sasaran pemasarannya.

Perusahaan terus mengoptimalkan seluruh sumber daya yang dimiliki dalam menghasilkan produk berkualitas tinggi agar mampu bertahan dalam persaingan tinggi agar mampu bertahan alam persaingan dengan perusahaan lain. Untuk memenuhi semua tantangan tersebut, perusahan membutuhkan analisis perencanaan strategis, tujuannya adalah untuk memperoleh keunggulan bersaing. Dengan demikian perusahaan mulai berfikir untuk menyusun suatu strategi pemasaran yang baik dan tepat. Pendekatan dalam menganalisa lingkungan bisnis perusahaan merupakan hal yang sangat penting mengingat faktor eksternal dan faktor internal lingkungan bisnis melahirkan kekuatan dan kelemahan serta peluang dan ancaman yang harus diperhatikan untuk diantisipasi keadaan tersebut karena 
perusahaan tidak ingin kehilangan kepercayaan dari pelanggannya.

Pada dasarnya analisis SWOT haruslah membandingkan kondisi sama yang dihadapi oleh pesaingnya berdasarkan kriteria subjektif ataupun objektif (skala industri), sebab dengan membandingkan maka perusahaan yang berkepentingan dapat menentukan rencana strategis untuk menghadapi persaingan tersebut. Akan tetapi bila perusahaan yang dimaksud hingga pada saat dilakukan kajian situasi ternyata tidak memiliki data tentang pesaing atau pesaingnya belum terpetakan baik dalam skala industri (kumpulan perusahaan yang menghasilkan barang yang sama) maupun dari hasil inteligen perusahaan, sedangkan perusahaan mendesak sekali untuk mempersiapkan rencana usaha strategis terutama dari segi pemasaran dan manajemen organisasi, maka dengan menggunakan analisis SWOT yang dimodifikasi sedemikian hingga menjadikan dapat digunakan oleh perusahaan tanpa harus mengetahui skala industri atau data inteligen mengenai pesaingnya. (Putong, 2003)

Persaingan industri yang sangat ketat, menuntut perusahaan meningkatkan kemampuannya agar dapat memenangkan persaingan dalam merebut pasar domestik. PT $\mathrm{X}$ terus melakukan inovasi yang berkaitan dengan strategi pemasaran yang bersifat strategis dalam rangka memenangkan persaingan. Dengan fenomena yang terjadi diperlukan suatu penelitian yang berkaitan dengan daya saing perusahaan dan usaha untuk dapat merebut pasar sehingga perusahaan dapat menentukan strategi pemasaran bisnis yang tepat bagi perusahaan.

\section{Rumusan Masalah}

Berdasarkan latar belakang yang telah dikemukakan maka rumusan masalahnya sebagai berikut :

1. Bagaimana strategi pemasaran yang dilakukan oleh PT X untuk membangun kekuatan, mengatasi kelemahan, mengeksploitasi peluang serta menghadapi ancaman yang dimiliki dan dihadapi dalam memasarkan produknya?

2. Bagaimana alternatif strategi pemasaran yang dapat digunakan PT X berdasarkan analisis SWOT dalam menghadapi persaingan bisnis di Indonesia ?

Batasan Masalah dalam penelitian ini, bahwa tidak memiliki data tentang pesaing atau pesaingnya belum terpetakan dalam skala industri maka tidak ada industri pembanding, sehingga analisa SWOT yang digunakan dengan menggunakan Analisa SWOT Tanpa Skala Industri (A SWOT TSI).

\section{METODE PENELITIAN}

a. Waktu dan Lokasi Penelitian

Penelitian ini dilakukan di industri alat berat yang berada di wilayah Jakarta. Penelitian dimulai pada bulan April 2017 sampai dengan bulan September 2017.

b. Metode Penelitian

Penelitian ini menggunakan metode penelitian deskriptif kuantitatif dengan menggambarkan fakta-fakta dan menjelaskan keadaan berdasarkan faktafakta dan data angka yang ada dan mencoba menganalisis kebenarannya melalui data yang diperoleh. Metode analisis yang digunakan yaitu Analisis SWOT TSI (Tanpa Skala Industri) dengan menggunakan metode analisis EFAS (analisis faktor eksternal) dan IFAS (analisis faktor internal) perusahaan. Teknik pengumpulan informasi yang dilakukan dengan cara menyusun daftar pertanyaan yang diajukan pada responden.

\section{HASIL DAN PEMBAHASAN}

Faktor Internal

1. Kekuatan (Strength)

a. PT X memiliki SDM yang dapat dapat diandalkan, yang digerakkan 
dengan suatu sistem manajemen terintegrasi untuk mencapai tujuan perusahaan secara terpadu.

b. Memiliki kualitas produk yang terjamin, yang dihasilkan tidak terlepas dari kebijakan mutu perusahaan, dengan produk yang telah memenuhi standar internasional.

c. Distributor tunggal yang dimiliki oleh perusahaan, merupakan salah satu wujud dari kepercayaan perusahaan terhadap PT X sebagai distributor peralatan berat.

d. Budaya Organisasi yang kuat, merupakan suatu yang dipegang teguh oleh seluruh karyawan untuk menciptakan suatu produk yang handal. Budaya perusahaan dapat membangkitkan semangat untuk bekerja lebih baik serta merangsang untuk menciptakan inovasi terbaru sehingga dapat tercipta peningkatan presetasi kerja karyawan.

\section{Kelemahan (Weakness)}

a. Jumlah tenaga teknisi untuk mesin konstruksi dinilai masih kurang, dalam penanganan rekondisi mesin

\section{Faktor Eksternal}

\section{Peluang (Opportunity)}

a. Pertumbuhan pasar yang baik, terkait dengan fleksibilitas ekpor mineral dan batubara mendorong aktivitas pertambangan bergairah. Pelayanan purna jual merupakan peluang usaha bagi perusahaan, PT $\mathrm{X}$ mengoptimalkan peluang usaha pada layanan purna jual untuk menjaga kondisi peralatan-peralatan yang dimiliki oleh konsumen. Pendapatan dari purnajual merupakan pendapatan yang sangat berarti dari lini usaha alat berat. Banyak alat-alat berat yang mengalami perbaikan mesin (maintenance) dan komponen lainnya untuk memperpanjang usia pakai sehingga perlu dibutuhkan tenaga teknisi dalam jumlah banyak untuk pelayanan perbaikan, merekondisi mesin dari pihak yang membutuhkan jasa PT X.

b. Jumlah kantor cabang, pendukung yang masih kurang, sehingga masih diperlukan penambahan kantor cabang dan pendukung agar lebih dapat menjangkau kebutuhan pelayanan yang ada di daerah terpencil.

c. Ketergantungan perseroan pada perjanjian dengan supplier dalam pengadaan unit barang yang secara keseluruhan masih impor. Ketika negosiasi membuat perjanjian posisi perusahaan pada posisi lemah.

d. Koordinasi yang kurang lancar antara para manager dengan karyawannya terutama koordinasi antar kantor pusat dan daerah sehingga menjadi hambatan bagi kemajuan perusahaan, apabila tidak ditangani dengan cepat maka dapat berdampak pada tingkat produktivitas karyawan.

kendaraan dan peralatan. Dengan ratarata periode perbaikan mesin lima tahun sekali, maka diprediksi akan menjadi puncak kegiatan maintenance bagi alat berat perusahaan.

b. Kemajuan teknologi mesin konstruksi yang semakin pesat, memberikan peluang bagi industri alat berat untuk dapat memberikan inovasi bagi kebutuhan industri alat berat.

c. Kebijakan pemerintah dalam membangun infrastruktur membutuhkan dukungan peralatan alat berat sehingga memberikan peluang bagi perusahaan untuk menjual dan menyewakan alat berat yang dibutuhkan dalam pembangunan infrastruktur. Selain itu juga pemerintah 
memberikan kemudahan impor peralatan alat berat yang belum di produksi dalam negeri yang berdampak terhadap keuntungan perusahaan.

d. Perdagangan bebas dan trend global sourcing juga merupakan suatu peluang yang dapat dimanfaatkan perusahaan apabila aturan dan syarat tersebut dapat dipenuhi perusahaan. Adanya trend global sourcing yang diterapkan oleh perusahaan dalam rangka mengefisienkan dan kompetitif untuk mencari keuntungan yang memadai bagi perusahaan. Dan Perusahaan bisa mencari sumber-sumber peralatan dari negara yang lebih kompetitif dengan perjanjian lebih saling menguntungkan.

\section{Ancaman (Threath)}

a. Bertambahnya jumlah pesaing pada pangsa pasar yang sama, dengan semakin banyaknya jumlah pesaing perusahaan alat berat yang berdampak kepada ketatnya persaingan

b. Perubahan teknologi yang cepat, merupakan ancaman serius bagi perusahaan industri alat berat karena perusahaan harus dapat mengikuti kemajuan perkembangan teknologi.

c. Lingkungan bisnis yang cepat berubah, merupakan ancaman karena apabila perusahaan tidak dapat beradaptasi dengan lingkungan dapat menghambat perkembangan operasi perusahaan, seperti diberlakukan nya kebijakan pelarangan ekspor untuk mineral dan batubara.

d. Kegiatan tambang yang tidak stabil, maka akan berpengaruh terhadap penjualan dan penyewaan alat berat. Berdasarkan UU mengenai pembatasan mineral dan batubara N0. 4 tahun 2009 yang melarang ekspor mineral dalam bentuk mentah yang mempengaruhi kegiatan usaha pertambangan.

Tabel.1

Sintesa Faktor Kekuatan dan Kelemahan

\begin{tabular}{|c|c|c|c|c|c|}
\hline $\mathrm{N}$ & Faktor - & $\mathrm{S}$ & $\mathrm{K}$ & $\mathrm{SP} \mathrm{X}$ & $\mathrm{BOBO}$ \\
$\mathrm{O}$ & Faktor & $\mathrm{P}$ & & $\mathrm{P}$ & $\mathrm{T}$ \\
\hline
\end{tabular}

\begin{tabular}{|c|c|c|c|c|c|}
\hline & $\begin{array}{l}\text { Strategi } \\
\text { Internal }\end{array}$ & & & & \\
\hline & $\begin{array}{l}\text { Kekuatan } \\
\text { (Strength) }\end{array}$ & & & & \\
\hline 1 & SDM & 2 & 4 & 8 & $\begin{array}{c}8 / 40= \\
0.2\end{array}$ \\
\hline 2 & $\begin{array}{l}\text { Kualitas } \\
\text { produk }\end{array}$ & 4 & 4 & 16 & $\begin{array}{c}16 / 40= \\
0.4\end{array}$ \\
\hline 3 & $\begin{array}{l}\text { Distributor } \\
\text { Tunggal }\end{array}$ & 3 & 4 & 12 & $\begin{array}{c}12 / 40= \\
0.3\end{array}$ \\
\hline 4 & $\begin{array}{l}\text { Budaya } \\
\text { Perusahaan }\end{array}$ & 1 & 4 & 4 & $\begin{array}{c}4 / 40= \\
0.1\end{array}$ \\
\hline & TOTAL & & & 40 & 1.0 \\
\hline & $\begin{array}{l}\text { Kelemahan } \\
\text { (Weakness) }\end{array}$ & & & & \\
\hline 1 & $\begin{array}{l}\text { Jumlah } \\
\text { tenaga teknisi } \\
\text { untuk mesin } \\
\text { konstruksi } \\
\text { kurang }\end{array}$ & 4 & 4 & 16 & 0.4 \\
\hline 2 & $\begin{array}{l}\text { Jumlah kantor } \\
\text { cabang dan } \\
\text { kantor } \\
\text { pendukungny } \\
\text { a masih } \\
\text { sedikit }\end{array}$ & 1 & 4 & 4 & 0.1 \\
\hline 3 & $\begin{array}{l}\text { Ketergantung } \\
\text { an perseroan } \\
\text { pada } \\
\text { perjanjian } \\
\text { dengan } \\
\text { supplier }\end{array}$ & 3 & 4 & 12 & 0.3 \\
\hline 4 & Koordinasi & 2 & 4 & 8 & 0.2 \\
\hline & TOTAL & & & 40 & 1.0 \\
\hline
\end{tabular}

1. Pembobotan tetap menggunakan skala 1 (sangat penting ) hingga 0 (tidak penting), akan tetapi penentuan nilai skala untuk masing-masing situasi total berjumlah 1 dengan cara:

a. Urutkan faktor situasi berdasarkan skala prioritas (SP) (tertinggi nilainya 16 dari $4 \times 4$, urutan 2 nilainya $3 \times 4=12$ dan terendah nilai 4 dari $1 \quad x \quad 4)$ lalu dikalikan dengan konstanta $(\mathrm{K})$ nilai tertinggi yaitu 4 
b. Masing-masing nilai situasi tersebut di bagi dengan total nilai SP x K

2. Peringkat tetap menggunakan skala 1(rendah) - 4 (tinggi) untuk kekuatan dan peluang, sedangkan skala 4(rendah) 1(tinggi) untuk kelemahan dan ancaman, namun karena tidak ada pembanding, maka nilai skala ditentukan berdasarkan prioritas dari masing-masing situasi (misalnya skala 4 untuk peluang yang paling utama)

3. Nilai tertinggi untuk Bobot $x$ Peringkat adalah 1-2 (Kuat) dan terendah adalah 01 (lemah)

Tabel.2

Sintesa Faktor Peluang dan Ancaman

\begin{tabular}{|c|c|c|c|c|c|}
\hline No & $\begin{array}{c}\text { Faktor } \\
\text { Strategi } \\
\text { Eksternal }\end{array}$ & $\begin{array}{l}S \\
P\end{array}$ & K & $\begin{array}{c}\text { SP X } \\
\text { P }\end{array}$ & $\begin{array}{c}\text { BOBO } \\
\mathrm{T}\end{array}$ \\
\hline & $\begin{array}{l}\text { Peluang } \\
\text { (Opportunit } \\
\text { y) }\end{array}$ & & & & \\
\hline 1 & $\begin{array}{l}\text { Pertumbuha } \\
\text { n pasar } \\
\text { yang baik }\end{array}$ & 4 & 4 & 16 & 0.4 \\
\hline 2 & $\begin{array}{l}\text { Kemajuan } \\
\text { teknologi } \\
\text { mesin } \\
\text { konstruksi } \\
\text { yang } \\
\text { semakin } \\
\text { pesat }\end{array}$ & 2 & 4 & 8 & 0.2 \\
\hline 3 & $\begin{array}{l}\text { Kebijakan } \\
\text { Pemerintah }\end{array}$ & 3 & 4 & 12 & 0.3 \\
\hline \multirow[t]{3}{*}{4} & $\begin{array}{l}\text { Perdaganga } \\
n \text { bebas }\end{array}$ & 1 & 4 & 4 & 0.1 \\
\hline & TOTAL & & & 40 & 1.0 \\
\hline & $\begin{array}{l}\text { Ancaman } \\
\text { (Threath) }\end{array}$ & & & & \\
\hline 1 & $\begin{array}{l}\text { Perubahan } \\
\text { teknologi } \\
\text { yang cepat }\end{array}$ & 1 & 4 & 4 & 0.1 \\
\hline 2 & Lingkungan & 2 & 4 & 8 & 0.2 \\
\hline
\end{tabular}

\begin{tabular}{|c|l|c|c|c|c|}
\hline & $\begin{array}{l}\text { bisnis yang } \\
\text { cepat } \\
\text { berubah }\end{array}$ & & & & \\
\hline 3 & $\begin{array}{l}\text { Bertambahn } \\
\text { ya jumlah } \\
\text { pesaing } \\
\text { pada pangsa } \\
\text { pasar yang } \\
\text { sama }\end{array}$ & 4 & 4 & 16 & 0.4 \\
\hline 4 & $\begin{array}{l}\text { Kegiatan } \\
\text { tambang } \\
\text { yang tidak } \\
\text { stabil }\end{array}$ & 3 & 4 & 12 & 0.3 \\
\hline & TOTAL & & 40 & 1.0 \\
\hline
\end{tabular}

Tabel 3

Faktor-Faktor Strategik Internal (IFAS)

\begin{tabular}{|c|c|c|c|c|}
\hline $\begin{array}{l}\mathrm{N} \\
\mathrm{O}\end{array}$ & $\begin{array}{c}\text { Faktor - } \\
\text { Faktor } \\
\text { Strategi } \\
\text { Internal }\end{array}$ & $\begin{array}{c}\text { BOB } \\
\text { OT }\end{array}$ & $\begin{array}{l}\text { PERIN } \\
\text { GKAT }\end{array}$ & $\begin{array}{c}\text { BOBO } \\
\text { T X } \\
\text { PERIN } \\
\text { GKAT }\end{array}$ \\
\hline & $\begin{array}{l}\text { Kekuatan } \\
\text { (Strength) }\end{array}$ & & & \\
\hline 1 & SDM & 0.2 & 4 & 0.8 \\
\hline 2 & $\begin{array}{l}\text { Kualitas } \\
\text { produk }\end{array}$ & 0.4 & 4 & 1.6 \\
\hline 3 & $\begin{array}{l}\text { Distributor } \\
\text { Tunggal }\end{array}$ & 0.3 & 4 & 1.2 \\
\hline 4 & $\begin{array}{l}\text { Budaya } \\
\text { Perusahaan }\end{array}$ & 0.1 & 4 & 0.4 \\
\hline & TOTAL & & & 4.0 \\
\hline & $\begin{array}{l}\text { Kelemahan } \\
\text { (Weakness) }\end{array}$ & & & \\
\hline 1 & $\begin{array}{l}\text { Jumlah } \\
\text { tenaga } \\
\text { teknisi untuk } \\
\text { mesin } \\
\text { konstruksi } \\
\text { kurang }\end{array}$ & 0.4 & 3 & 1.2 \\
\hline 2 & $\begin{array}{l}\text { Jumlah } \\
\text { kantor } \\
\text { cabang dan } \\
\text { kantor } \\
\text { pendukungn } \\
\text { ya masih } \\
\text { sedikit }\end{array}$ & 0.1 & 2 & 0.2 \\
\hline 3 & Ketergantun & 0.3 & 2 & 0.6 \\
\hline
\end{tabular}




\begin{tabular}{|l|l|l|l|l|}
\hline $\begin{array}{l}\text { gan } \\
\text { perseroan } \\
\text { pada } \\
\text { perjanjian } \\
\text { dengan } \\
\text { supplier }\end{array}$ & & & \\
\hline 4 & Koordinasi & 0.2 & 2 & 0.4 \\
\hline & TOTAL & & & 2.4 \\
\hline
\end{tabular}

Tabel 4

Faktor-Faktor Strategik Eksternal (EFAS)

\begin{tabular}{|c|c|c|c|c|c|c|}
\hline \multicolumn{4}{|c|}{ Faktor-Faktor Strategik Eksternal (EFAS) } & & \multirow{2}{*}{$\begin{array}{l}=4.0+3.6 \\
=7.6\end{array}$} & \multirow{2}{*}{$\begin{array}{l}=2.4+3.6 \\
=6.0\end{array}$} \\
\hline \multirow[t]{2}{*}{ No } & Faktor - & BOBOT & PERINGKAT & BOBOT X & & \\
\hline & $\begin{array}{c}\text { Faktor } \\
\text { Strategi } \\
\text { Eksternal }\end{array}$ & & & PERredithKA)T & \multirow{2}{*}{$\begin{array}{l}\text { Strategi }(\mathrm{ST}) \\
: \\
=4.0+2.6 \\
=6.6\end{array}$} & \multirow{2}{*}{$\begin{array}{l}\text { Strategi (WT) } \\
: \\
=2.4+2.6 \\
=4.8\end{array}$} \\
\hline & Peluang & & & & & \\
\hline & (Opportunity) & & & & & \\
\hline
\end{tabular}

Tabel.5

Rumusan Strategi Matrik SWOT

\begin{tabular}{|c|c|c|}
\hline $\begin{array}{l}\text { IFAS } \\
\text { EFAS }\end{array}$ & Strength $(\mathrm{S})$ & $\begin{array}{l}\text { Weakness } \\
\text { (W) }\end{array}$ \\
\hline $\begin{array}{l}\text { Opportunity } \\
\text { (O) } \\
\text { BOBOT X }\end{array}$ & $\begin{array}{l}\text { Strategi } \\
(\mathrm{SO}): \\
=4.0+3.6 \\
=7.6\end{array}$ & $\begin{array}{l}\text { Strategi }(\mathrm{WO}) \\
: \\
=2.4+3.6 \\
=6.0\end{array}$ \\
\hline PERHAd(TKA)T & $\begin{array}{l}\text { Strategi }(\mathrm{ST}) \\
: \\
=4.0+2.6 \\
=6.6\end{array}$ & $\begin{array}{l}\text { Strategi (WT) } \\
: \\
=2.4+2.6 \\
=4.8\end{array}$ \\
\hline
\end{tabular}

Berdasarkan tabel IFAS dan EFAS di atas, mak .6dapat dibuat Matriks SWOT yang terdiri atas 4 kuadran ( 9 sel) seperti yang ditunjukkan sebagai berikut:

Tabel 6

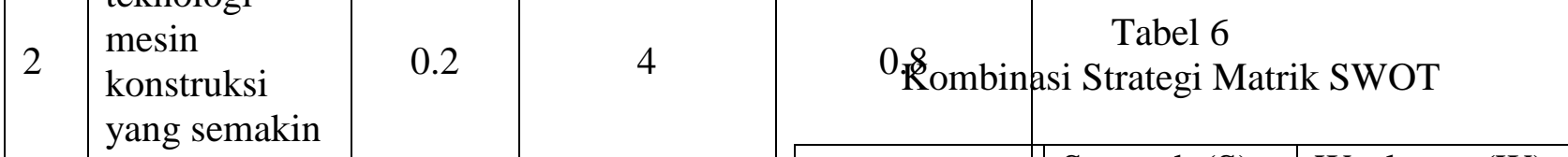

\begin{tabular}{|c|c|c|c|c|c|c|}
\hline & & & & & \multirow{11}{*}{\begin{tabular}{|l} 
Strength (S) \\
1. SDM \\
2. Kualitas \\
produk \\
terjamin \\
3. Distributor \\
Tunggal \\
4. Budaya \\
perusahaa \\
n
\end{tabular}} & \multirow{11}{*}{$\begin{array}{l}\text { Weakness (W) } \\
\text { 1. Jumlah } \\
\text { tenaga } \\
\text { teknisi } \\
\text { untuk } \\
\text { mesin } \\
\text { konstruksi } \\
\text { kurang } \\
\text { 2. Jumlah } \\
\text { kantor } \\
\text { cabang dan } \\
\text { kantor } \\
\text { pendukung } \\
\text { nya masih } \\
\text { sedikit } \\
\text { 3. Ketergantu } \\
\text { ngan } \\
\text { perseroan } \\
\text { pada } \\
\text { perjanjian } \\
\text { dengan } \\
\text { supplier } \\
\text { 4. Koordinasi }\end{array}$} \\
\hline & pesat & & & & & \\
\hline 3 & $\begin{array}{l}\text { Kebijakan } \\
\text { Pemerintah }\end{array}$ & 0.3 & 3 & $\begin{array}{r}\text { IFAS } \\
0.9\end{array}$ & & \\
\hline \multirow[t]{4}{*}{4} & $\begin{array}{l}\text { Perdagangan } \\
\text { bebas }\end{array}$ & 0.1 & 3 & 0.3 & & \\
\hline & TOTAL & & & \multirow{2}{*}{ EFAS } & & \\
\hline & & & & & & \\
\hline & $\begin{array}{l}\text { Ancaman } \\
\text { (Threath) }\end{array}$ & & & & & \\
\hline 1 & $\begin{array}{l}\text { Perubahan } \\
\text { teknologi } \\
\text { yang cepat }\end{array}$ & 0.1 & 2 & 0.2 & & \\
\hline 2 & $\begin{array}{l}\text { Lingkungan } \\
\text { bisnis yang } \\
\text { cepat berubah }\end{array}$ & 0.2 & 3 & 0.6 & & \\
\hline 3 & $\begin{array}{l}\text { Bertambahnya } \\
\text { jumlah } \\
\text { pesaing pada } \\
\text { pangsa pasar } \\
\text { yang sama }\end{array}$ & 0.4 & 3 & 1.2 & & \\
\hline 4 & $\begin{array}{l}\text { Kegiatan } \\
\text { tambang yang } \\
\text { tidak stabil }\end{array}$ & 0.3 & 2 & \multirow[b]{2}{*}{$\begin{array}{l}\text { Opportunity } \\
\text { (O) }\end{array}$} & & \\
\hline & & & & & $\begin{array}{l}\text { Strength - } \\
\text { Opportunity }\end{array}$ & $\begin{array}{l}\text { Weakness - } \\
\text { Opportunity }\end{array}$ \\
\hline
\end{tabular}




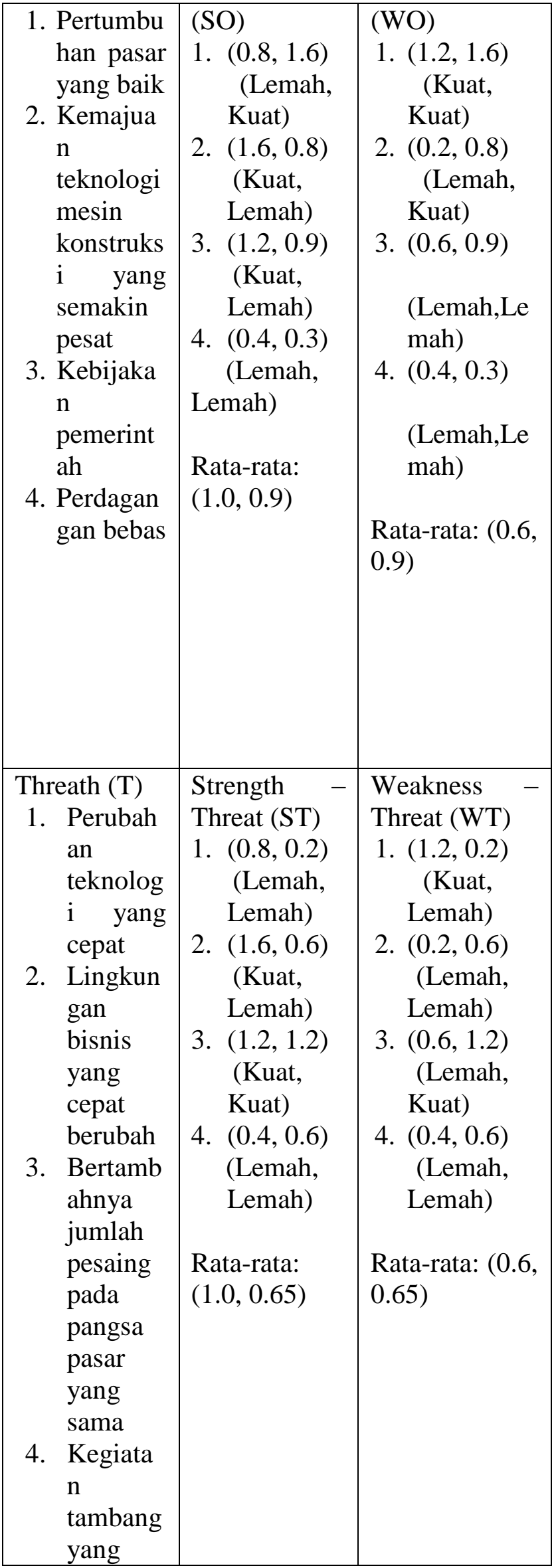

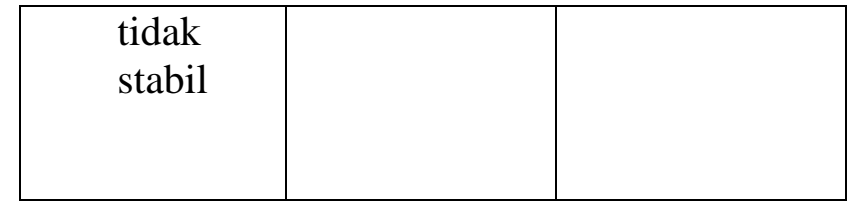

Perumusan Strategi

Berdasarkan analisis SWOT maka Analisis Strategi bagi semua Situasi (SO, WO, ST, dan WT yang dilakukan sebagai berikut :

1. Kualitas Produk yang dipasarkan oleh PT $\mathrm{X}$ mempunyai kualitas yang sangat kuat atau baik, dan Citra merek sangat kuat dalam mendukung pengembangan pasar dan segmen pasar untuk memanfaatkan peluang pasar. Kecenderungan pertumbuhan pasar yang baik di mungkinkan untuk melakukan pengembangan pasar ke wilayah geografi yang baru dengan penetrasi pasar yaitu, mencari pangsa pasar yang lebih besar untuk produk yang sudah ada dengan usaha pemasaran yang lebih gencar.

2. Jumlah tenaga kerja teknisi dengan pertumbuhan pasar mempunyai hubungan yang kuat, maka diharapkan pihak PT X segera menambah dan mempersiapkan tenaga kerja teknisi yang professional agar dapat memanfaatkan peluang dalam hal pelayanan purna jual, salah satu kekuatan utama terletak pada layanan purna jual, yang ditujukan untuk melayani kebutuhan pelanggan setelah transaksi jual-beli alat berat dan pada saat bersamaan turut menyumbangkan pendapatan yang menguntungkan yaitu jasa yang ditawarkan dalam layanan purna jual meliputi konsultasi pra-penjualan, penyediaan suku cadang, pemeliharaan alat hingga pelatihan bagi operator

Alternatif Strategi

Analisis alternatif strategi berdasarkan hasil Matrik SWOT secara umum bila memperhatikan rata-rata dari setiap strategi antar situasi yang terdapat dalam matriks SWOT menunjukkan bahwa untuk Analisa 
SO yaitu kekuatan dan kesempatan atau peluang dalam perusahaan strategi (SO) yang bisa diraih menunjukkan bahwa Strength (S) > Opportunity $(\mathrm{O})$, Kekuatan lebih besar dari pada peluangnya sehingga dapat digunakan strategi SO dengan menggunakan kekuatan untuk memanfaatkan peluang, memiliki sumber daya manusia (SDM) yang berkualitas dan dapat diandalkan, yang digerakkan dengan suatu sistem manajemen untuk mendapatkan peluang dalam penetrasi pasar yaitu, mencari pangsa pasar yang lebih besar untuk produk yang sudah ada dengan usaha pemasaran yang lebih gencar.

Analisis Strategi WO, menunjukan bahwa Opportunity $(\mathrm{O})>$ Weakness $(\mathrm{W})$, peluang lebih besar daripada kelemahan. Hal ini melihat bahwa peluang untuk masuk dalam mengambil pertumbuhan pasar yang baik dalam hal infrastruktur dimana Industri konstruksi yang sedang tumbuh, berdampak signifikan terhadap PT $\mathrm{X}$ dan didukung pertumbuhan sektor konstruksi lebih tinggi dibandingkan sektor tambang sehingga mengingat kelemahan relatif kecil maka bisa membenahi faktor internal dan eksternalnya terutama dengan segera menambah dan melatih SDM khususnya tenaga teknisi yang professional.

Analisis Strategi ST, menunjukkan bahwa Strength(S) > Threat (T), kekuatan lebih besar dari ancaman dengan menggunakan kondisi kekuatan untuk mengatasi ancaman yang ada dengan cara mempertahankan kualitas produk saat ini dan mempertahankan sebagai distributor peralatan berat di Indonesia yang menyediakan produk-produk dari merek ternama dunia sehingga tidak terpengaruh penjualannya dengan bertambahnya jumlah pesaing pada pangsa pasar yang sama.

Analisis Strategi WT, menunjukkan bahwa Threat (T) > Weakness (W), Ancaman lebih besar daripada Kelemahan dengan meminimalkan kelemahan untuk menghindari ancaman yang ada. Kondisi ini harus diperhatikan karena ancaman yang besar di iringi oleh kelemahan yang terdapat pada perusahaan dengan bertambahnya jumlah pesaing pada pangsa pasar yang sama terutama pesaing dari negeri Tiongkok dengan menjual produk dengan harga yang lebih murah maka PT $X$ harus mampu mempertahankan pangsa pasar yang ada dengan tetap mengedepankan kualitas produk untuk tetap memberikan kepuasan pada pelanggan

\section{KESIMPULAN}

Berdasarkan pembahasan diatas, maka kesimpulan sebagai berikut :

1. Perhitungan analisis EFAS dan IFAS, menunjukkan bahwa PT $X$ dalam menggunakan SWOT Tanpa Skala Indusri (TSI) menempatkan strategi Strength (S) $>$ Opportunity $(\mathrm{O})$, Strategi Opportunity (O) > Weakness (W), Strategi Strength (S) $>$ Threat $(\mathrm{T})$ dan Strategi Threat > Weakness (W). Kondisi ini bahwa PT X berada pada posisi memanfaatkan strategi SO yang mempunyai nilai skor tertinggi yaitu $=7.6$, selanjutnya diikuti strategi $\mathrm{ST}=6.6, \mathrm{WO}=6.0$ dan $\mathrm{WT}=4.8$.

2. Dengan melakukan analisis SWOT TSI (tanpa skala industri) strategi yang akan dilakukan oleh perusahaan dengan mempertahankan citra merek perusahaan dengan menjaga pangsa pasar yang ada serta penetrasi pasar berupaya untuk menguasai pangsa pasar yang lebih besar.

Berdasarkan hasil tersebut, maka saran yang dapat diberikan yaitu dengan melakukan peningkatan kualitas SDM terutama tenaga di bidang teknisi dengan melakukan pelatihan di dalam negeri maupun luar negeri sehingga dapat menciptakan modifikasi dan inovasi dalam bisnis industri alat berat.

\section{DAFTAR PUSTAKA}

Amstrong, Kotler, Philip. 2010. Manajemen Pemasaran, Analisis, Perencanaan, Implementasi.. Jilid 2. PT. Prenhallindo, Jakarta 
David. Fred R. 2002. Manajemen Strategi Konsep. PT. Prenhallindo, Jakarta

Kotler, Philip Dan Kevin Lane Keller. 2007. Manajemen Pemasaran. Edisi Kedua Belas.Jakarta

Putong, Iskandar. 2003. Jurnal ilmiah Ekonomi \& Bisnis vol. 8 no. 2, Penerbit Universitas Gunadarma, Jakarta

Rangkuti, F. 2005. Analisis SWOT Teknik Membedah Kasus Bisnis. PT. Gramedia Pustaka Utama, Jakarta

Tjiptono, Fandy dan Anastasia Diana. 2003. Strategi Bisnis Modern. Andy: Yogyakarta

Umar, Husein. 2001. Strategic Management in Action, Gramedia Pustaka Utama : Jakarta 